\title{
Spectroscopically Encoded Microspheres for Antigen
}

\section{Biosensing}

Jose Raez, ${ }^{a}$ David R. Blais, ${ }^{b}$ Ying Zhang, ${ }^{a}$ Ramon A. Alvarez-Puebla, ${ }^{a}$ Juan P. Bravo-Vasquez, ${ }^{a}$ John P. Pezacki, ${ }^{b, c^{*}}$ and Hicham Fenniri ${ }^{a, d^{*}}$

${ }^{a}$ National Institute for Nanotechnology, 11421 Saskatchewan Drive, Edmonton, AB, Canada, T6G 2M9. ${ }^{b}$ Steacie Institute for Molecular Sciences, 100 Sussex Drive, Ottawa, ON, Canada, K1A 0R6. ${ }^{c}$ Department of Chemistry, University of Ottawa, 10 Marie-Curie, Ottawa, ON, Canada, K1N 6N5. ${ }^{d}$ Department of Chemistry, University of Alberta, 11227 Saskatchewan Drive, Edmonton, AB, Canada, T6G 2G2.

\footnotetext{
*Corresponding authors:

e-mail: john.pezacki@nrc-cnrc.gc.ca

fax: (613) 941-8447

e-mail: hicham.fenniri@nrc-cnrc.gc.ca

fax: (780) 641-1601
} 


\section{Experimental section}

Chemicals. All chemical reagents were purchased from Sigma (St. Louis, MO), unless otherwise indicated. Cy3-labeled monoclonal anti-rabbit IgG antibody (Ab1) supplied with 15 $\mathrm{mg} / \mathrm{mL}$ BSA and Cy2-labeled rabbit IgG antigen (Ag1) were obtained from Jackson ImmunoResearch (West Grove, PA).

Carboxylated BCR synthesis. The co-monomers (4-methylstyrene, 4-t-butylstyrene, 2,4dimethylstyrene, 2,5-dimethylstyrene) and the cross-linker (DVB, 1,4-divinylbenzene) were washed with sodium hydroxide, distilled under reduced pressure to remove the stabilizer, and stored at $4^{\circ} \mathrm{C}$. The beads were synthesized by dispersion polymerization. Typically, a solution composed of the DVB (170 $\mu \mathrm{L})$, benzoyl peroxide $(0.2 \mathrm{~g}$, recrystallized twice from methanol), methacrylic acid (738 $\mu \mathrm{L}, 8.7 \mathrm{mmol}$, distilled under reduced pressure) and the styrene comonomer $(87 \mathrm{mmol})$ was flushed with Argon $(20 \mathrm{~min})$, then added to a Morton reactor equipped with a mechanical stirrer, condenser, $\mathrm{N}_{2}$ inlet, and containing $70 \mathrm{~mL}$ of a $0.1 \% \mathrm{w} / \mathrm{v}$ solution of polyvinyl alcohol (PVA, 87-89\% hydrolyzed, molecular weight: 85,000-146,000) in deionized water $\left(\mathrm{dH}_{2} \mathrm{O}\right)$. The mixture was stirred at a fixed speed $(330 \mathrm{rpm})$ at room temperature for 30 $\min$, then at $85^{\circ} \mathrm{C}$ for $24 \mathrm{~h}$. The beads formed were sieved $(45 \mu \mathrm{m})$, thoroughly washed with $\mathrm{dH}_{2} \mathrm{O}$ and methanol (soxhlet extractor, $24 \mathrm{~h}$ each), and vacuum-dried for $24 \mathrm{~h}$.

Antibody conjugation and immunoassay. Carbodiimide chemistry was used to conjugate the primary amines of the antibody with the carboxyl groups on the BCRs (Figure 1). Typically, the BCR (0.15 g) and 1-ethyl-3(3-dimethylaminopropyl)-carbodiimide (EDC) conjugation buffer (50 $\mu \mathrm{L}, 2 \% \mathrm{w} / \mathrm{v}$ EDC in phosphate buffer saline, $\mathrm{pH} 8.0$ ) were mixed in an orbital shaker for 10 min at room temperature before the $\mathrm{Ab} 1(0.75 \mu \mathrm{g}$ or $75 \mu \mathrm{g}$ in $5 \mu \mathrm{L})$ was added. The reaction mixture was incubated at $37^{\circ} \mathrm{C}$ for $24 \mathrm{~h}$ on an orbital shaker then quenched with hydroxylamine 
$(1 \mathrm{M}, 10 \mu \mathrm{L})$. Ab1-BCR conjugates were washed with PBS $(3 \times 1 \mathrm{~mL})$ and collected by centrifugation $(1000 \mathrm{Xg}, 1 \mathrm{~min})$. The conjugation of $\mathrm{Ab} 1$ to the BCRs was confirmed by fluorescence microscopy (Olympus IX81, Olympus, Centre Valley, PA).

The activity of Ab1-BCR conjugate was determined by analyzing its affinity toward its antigen (Ag1). Typically, Ab1-BCR (1 mg) was treated with postcoat buffer $(1 \mathrm{~mL}, 1 \% \mathrm{w} / \mathrm{v}$ BSA, $50 \mathrm{mM}$ Tris, $0.14 \mathrm{M} \mathrm{NaCl}, \mathrm{pH} 8.0$ ) for $1 \mathrm{~h}$ at room temperature to prevent non-specific adsorption of the antigen to the bead surface. The beads were washed with wash buffer $(1 \mathrm{~mL}$, $50 \mathrm{mM}$ Tris, $0.14 \mathrm{M} \mathrm{NaCl}, 0.05 \%$ v/v Tween-20, pH8.0), incubated with Ag1 (0.15 $\mu \mathrm{g} / \mathrm{mL}$ or 15 $\mu \mathrm{g} / \mathrm{mL})$ on an orbital shaker for $1 \mathrm{~h}$ at room temperature, then washed $(4 \times 1 \mathrm{~mL}$ wash buffer) to remove unbound antigen. The on-bead Ab1-Ag1 association was confirmed by visualizing Ag1 fluorescence.

Raman and fluorescence spectroscopy. Inelastic scattering of the beads was recorded on a Nicolet Almega XR Dispersive Raman spectrometer (Thermo Fisher Scientific, Waltham, MA) in high-resolution mode using multiple gratings $(2400 \mathrm{~g} / \mathrm{mm})$ and two excitation lines (532/780 $\mathrm{nm})$. The laser beam $(780 \mathrm{~nm}, 2.4 \mathrm{~mW}$ at the sample) was focused onto the sample with a $10 \times$ microscope objective (spatial resolution of $\sim 10 \mu \mathrm{m}$ ), and $2 \times 1 \mathrm{~s}$ scans were accumulated. Fluorescence of the $\mathrm{Cy} 2 / \mathrm{Cy} 3$ dyes was recorded on the same instrument by exciting the samples $(1 \times 0.1 \mathrm{~s})$ with the visible laser $(532 \mathrm{~nm})$ in low-resolution mode $(1200 \mathrm{~g} / \mathrm{mm}$ grating). Raman/fluorescence mapping of the bead mixture deposited on a glass slide was carried out under the same conditions described above. Total size of the map was $345 \times 450 \mu \mathrm{m}^{2}$, with a step size of $15 \mu \mathrm{m}$. Spectra collected in this mode were then compared, using a partial least square algorithm (Omnic 7.5 software, Thermo Electron Co) against a previously created database of the Raman spectra of all the BCRs. Solution for the deconvolution is shown in Figure 3F. 